\title{
A hospital-based study of severe acute malnutrition in infants less than six months and comparison with severe acute malnutrition in children 6-60 months
}

\author{
Syed Manazir Ali ${ }^{1}$, *Hari S Meshram ${ }^{1}$ \\ Sri Lanka Journal of Child Health, 2017; 46(3): 234-237
}

\begin{abstract}
Introduction: Severe acute malnutrition (SAM) in infants less than 6 months of age is not rare. There is a lack of studies in this age group in the literature.

Objective: To study the clinical and laboratory characteristics, comorbidities and outcome of SAM in infants less than 6 months of age and compare them with SAM in children 6-60 months of age in the Nutritional Rehabilitation Centre (NRC) of the Department of Paediatrics, Jawaharlal Nehru Medical College Hospital (JNMCH), Aligarh Muslim University, Uttar Pradesh, India
\end{abstract}

Method: A hospital-based prospective observational study was conducted from January 2013 to October 2014 on children aged 1 to 60 months admitted to the NRC of the Department of Paediatrics, JNMCH. SAM was identified and managed as per WHO protocols. We studied the clinical and laboratory characteristics, comorbidities and outcome of SAM infants less than 6 months of age and compared them with SAM aged 660 months. Statistical analysis was done, using SPSS 17 for Windows Software.

Results: A total of 72 cases of SAM less than 6 months of age were admitted. Lack of breast feeding $(93 \%)$ was the main contributory reason for SAM in this age group. Anaemia (80\%), diarrhoea (59\%) and pneumonia $(29 \%)$ were the most frequent comorbidities encountered. There were 2 deaths giving a case fatality rate of $2.8 \%$, Sixty six $(92 \%)$ patients were discharged from hospital. Forty four (61\%) patient recovered. Seventeen (24\%) patients defaulted. Mean weight gain was $11 \mathrm{~g} / \mathrm{kg} /$ day and the

${ }^{1}$ Department of Paediatrics, Jawaharlal Nehru Medical College, AMU, Aligarh, Uttar Pradesh, India *Correspondence:harishankarmeshram11@gmail.com (Received on 14 November 2016: Accepted after revision on 23 December 2016)

The authors declare that there are no conflicts of interest

Personal funding was used for the project.

Open Access Article published under the Creative Commons Attribution CC-BY (CC) (i) mean length of stay was 13 days. On comparison with 227 cases of SAM aged 6-60 months, uraemia $(\mathrm{P}<0.01)$ and leucocytosis $(\mathrm{P}<0.05)$ were significantly more common in children with age group less than 6 months whilst anaemia $(\mathrm{P}<0.01)$ was significantly more common in children with age group 6-60 months.

Conclusions: Lack of breast feeding (93\%) was the main contributory factor for SAM in the less than 6 month age group. Uraemia and leucocytosis were significantly associated with SAM in children less than 6 months of age compared to SAM aged $6-60$ months in this study done in the NRC of the Department of Paediatrics, JNMCH, Aligarh Muslim University, Uttar Pradesh, India.

DOI: http://dx.doi.org/10.4038/sljch.v46i3.8324

(Key words: Severe acute malnutrition, less than 6 months)

\section{Introduction}

Severe acute malnutrition (SAM) in infants less than 6 months of age is defined as weight-for-length less than -3 Z-score or presence of bilateral pitting oedema ${ }^{1}$. SAM in infants less than 6 months of age is not rare ${ }^{1}$. Lack of breast feeding practices has been found to be the culprit for SAM in this age group ${ }^{2}$. Mortality associated with SAM is high in infants compared to children $^{3}$. There is a lack of systemic reporting of SAM in this age group and a lack of literature on clinical and laboratory characteristics of SAM in infants less than 6 months of age.

\section{Objective}

To study the clinical and laboratory characteristics, comorbidities and outcome of SAM in children less than 6 months of age and to compare them with SAM in children 6-60 months in the Nutritional Rehabilitation Centre of the Department of Paediatrics, Jawaharlal Nehru Medical College Hospital (JNMCH), Aligarh Muslim University, Uttar Pradesh, India 


\section{Method}

A hospital-based prospective observational study was conducted from January 2013 to October 2014 on children aged 1 to 60 months admitted to the NRC of the Department of Paediatrics, JNMCH. A complete history was taken and a systemic examination of SAM children was done. Comorbidities were identified and managed according to the World Health Organisation (WHO) protocol for the management of SAM. The haemoglobin $(\mathrm{Hb})$ level was estimated using a LabLife 3D haematological autoanalyser. A Hb level of less than $11 \mathrm{~g} / \mathrm{dl}$ was the cut off value for anaemia in children aged 6-60 months ${ }^{4}$. Due to the lack of diagnostic criteria of anaemia for children under 6 months of age, the same cut off value which is accepted in clinical practice ${ }^{5}$ was adopted. Total leucocyte count (TLC) was also estimated by the LabLife 3D haematological autoanalyser. TLC less than 4,000 cells/cu mm was taken as leucopenia and TLC more than 16,000 cells/cu mm was taken as leucocytosis. Random blood glucose (RBG) was estimated by Accu-Check ${ }^{\circledR}$ Active (Roche Diagnostics GmbH 68298 Mannheim, Germany). RBG less than $54 \mathrm{mg} \%$ was taken as hypoglycaemia as per WHO SAM protocol.

Blood urea values greater than $40 \mathrm{mmol} / \mathrm{l}$ and serum creatinine values greater than $0.90 \mathrm{mg} / \mathrm{dl}$ were considered to be high. Serum sodium less than $135 \mathrm{mEq} / 1$ was taken as hyponatraemia. Serum potassium less than $3.5 \mathrm{mEq} / 1$ was taken as hypokalaemia. Thyroid profile was done to detect hypothyroidism, Urine full report and culture were done to detect occult urinary tract infections. A comparison of the clinical profile and outcome between SAM aged less than 6 months and SAM in 660 months age groups was made. Statistical analysis was done, using the statistical package for social science (SPSS 17) for Windows Software. Continuous variables were expressed as means, standard deviation (SD), confidence intervals $(95 \% \mathrm{CI})$, frequency and range. $\mathrm{P}$ value $<0.05$ was taken as significant. Univariate analysis was done for computing association of factors separately. Multilogistic regression analysis was done for finding associations of dependent factors in relation to other factors.

\section{Results}

Of the total 299 cases $72(24 \%)$ children were less than 6 months of age and 227 (76\%) 6-60 months of age. Study was male predominant $(59 \%)$ with no statistically significant difference in sex. Seven percent of young infants were exclusive breast fed. Comorbidities found in the study included anaemia $(80 \%)$, diarrhoea $(59 \%)$, pneumonia $(29 \%)$, urinary tract infection (11\%), otitis media $(27 \%)$, and hypothyroidism (4\%). Of the 72 children less than 6 months of age, $66(92 \%)$ were discharged from hospital, $44(61 \%)$ recovered, 05 (7\%) left against medical advice and $01(1 \%)$ absconded. Five $(7 \%)$ of patients relapsed and 17 (24\%) defaulted. There were 2 deaths giving a case fatality rate of $2.8 \%$. Mean (SD) weight gain was $11(9.1) \mathrm{g} / \mathrm{kg} /$ day and mean length of stay was 6.6 days (range 2-49).

Table I compares the clinical and laboratory characteristics of SAM in the less than 6 months and 6 - 60 months age groups.

Table 1: Comparison of clinical and laboratory characteristics of severe acute malnutrition in less than 6 months and 6 or more months age groups

\begin{tabular}{|c|c|c|c|c|c|c|}
\hline Characteristic & $\begin{array}{c}<6 \text { months } \\
(n=72)\end{array}$ & $\begin{array}{c}6 \text { or }>\text { months } \\
(n=227)\end{array}$ & $P$ value & Odds ratio & \multicolumn{2}{|c|}{$\begin{array}{l}\text { 95.0\% confidence interval } \\
\text { Lower } \quad \text { Higher }\end{array}$} \\
\hline Male Sex & 43 & 143 & 0.48 & 0.8 & 0.47 & 1.40 \\
\hline Pneumonia & 21 & 70 & 0.56 & 0.81 & 0.45 & 1.44 \\
\hline Diarrhoea & 43 & 140 & 0.33 & 0.78 & 0.60 & 1.80 \\
\hline Anaemia & 58 & 210 & 0.001 & 0.18 & 0.08 & 0.41 \\
\hline Leucopenia & 05 & 08 & 0.36 & 1.64 & 0.53 & 5.11 \\
\hline Leucocytosis & 23 & 42 & 0.04 & 1.88 & 1.40 & 3.40 \\
\hline Uraemia & 36 & 58 & 0.001 & 2.8 & 1.60 & 4.90 \\
\hline Deranged creatinine & 30 & 81 & 0.48 & 1.2 & 0.70 & 2.10 \\
\hline Hypoglycaemia & 10 & 32 & 0.85 & 1.1 & 0.59 & 2.10 \\
\hline Hyponatraemia & 42 & 121 & 0.58 & 1.19 & 0.69 & 2.06 \\
\hline Hypokalaemia & 18 & 48 & 0.50 & 1.2 & 0.66 & 2.30 \\
\hline
\end{tabular}

Uraemia $(\mathrm{P}<0.01)$ and leucocytosis $(\mathrm{P}<0.05)$ were significantly more common in children with age group less than 6 months whilst anaemia $(\mathrm{P}<0.01)$ was significantly more common in children with age group 6 months or greater (Table 1). Other variables were found to be statistically insignificant. 


\section{Discussion}

There is a misconception that SAM in infants less than 6 months of age is rare. Only $7 \%$ of young infants were exclusively breast fed and $92 \%$ of the mothers had insufficient milk issues as a reason for introduction of top feeding in our study and hence babies were shifted to top feeding. This could be the main contributory factor for SAM in young infants.

Comorbidities encountered in SAM were the main hindrances in its management and the main reasons for treatment failure and prolonged length of stay in NRC. Anaemia (80\%), diarrhoea (59\%), pneumonia (29\%), urinary tract infection (11\%), otitis media $(27 \%)$ and hypothyroidism (4\%) were the common comorbidities encountered in this study. Unfortunately, there is a lack of published data regarding these comorbidities in young infants with SAM. Association of leucocytosis and uraemia in SAM in young infants as compared to 6-60 months in our study is a new finding which cannot be compared due to the paucity of studies in the literature. This finding can be explained on the basis that SAM in infants less than 6 months of age are more prone to infection and dehydration. This emphasises the need to detect subclinical infections in this age group for effective management of SAM and this be challenging. Anaemia, mostly due to nutritional causes, was found to be more common in SAM aged 6-60 months.

In our study, of the 72 children less than 6 months of age, $91 \%$ of cases were discharged as per Operational guideline on facility based management of SAM $2011^{6,7}$. This was higher than the national and international standard of care $(>75 \%)$ for programmes that treat children with $\mathrm{SAM}^{6,7}$. Intractable sepsis was the reason for the deaths during the study period. There was no significant difference in outcome indicators in both age groups. The length of stay was 13 days (2-45) and there was no significant difference with SAM aged 6-60 months. The average weight gain was $11 \mathrm{~g} / \mathrm{kg} / \mathrm{day}$ which is acceptable at nationally and internationally-agreed upon minimum average weight gain $(>8 \mathrm{~g} / \mathrm{kg}$ body weight/day) for programmes that treat children with SAM as per Operational guideline on facility based management of SAM $2011^{7,8}$. There are no specific Sphere indicators for infants aged $<6$ months and so outcomes were compared with guidelines for SAM aged 6-60 months ${ }^{8}$. This again highlights the need of enlarging our horizon for better management of SAM in young infants. This age group has been neglected when compared to the development made in the management of SAM aged 6 -60 months ${ }^{9}$.
The problem of SAM in young infants has always been overlooked. Management of SAM in young infants is different from that in children aged 6-60 months and with effective implementation of the WHO protocol, case fatality rate and other outcomes can be improved in this age group.

\section{Conclusions}

- Lack of breast feeding (93\%) was the main contributory factor for SAM in the less than 6 month age group.

- Uraemia and leucocytosis were significantly associated with SAM in children less than 6 months of age compared to SAM aged $6-60$ months in this study done in the NRC of the Department of Paediatrics, JNMCH, Aligarh Muslim University, Uttar Pradesh, India.

\section{Acknowledgements}

We are thankful to Mission director, Amit Ghosh, Dr. Hari Om Dikshit, Dr. Anil Verma, General Manager NHM and Neelofer UNICEF for their special support.

\section{References}

1. Kerac M, Blencowe H, Grijalva-Eternod C, McGrath M, Shoham J, Cole TJ, et al. Prevalence of wasting among under 6-monthold infants in developing countries and implications of new case definitions using WHO growth standards: a secondary data analysis. Archives of Disease in Childhood 2011; 96:1008-13. https://doi.org/10.1136/adc.2010.191882 PMid: 21288999 PMCid: PMC3195296

2. Black RE, Victoria CG, Walker SP, Bhutta ZA, Christian P, de Onis M, et al. Maternal and child undernutrition and overweight in low-income and middle income countries. Lancet 2013; 382(9890):427-51 https://doi.org/10.1016/S01406736(13)6093 $7-\mathrm{X}$

3. Briend A, Maire B, Fontaine O, Garenne M. Mid-upper arm circumference and weightfor-height to identify high-risk malnourished under-five children. Maternal and Child Nutrition 2012; 8:130-3. https://doi.org/10.1111/j.17408709.2011.003 40.x

PMid: 21951349

4. Stoltzfus RJ, Dreyfuss ML (1998) Guidelines for the use of iron supplements to prevent and treat iron deficiency anaemia. International 
Nutritional Anaemia Consultative Group / UNICEF / WHO. Available from:

http://motherchildnutrition.org/nutritionprotection-promotion/pdf/mon-guidelinesfor-iron-supplementation.pdf

5. Wintrobe M, Lee GR, Bogs TR, Bithell TC, Foerster J, et al. Clinical Haematology. 8th ed. Philadelphia: Lea \& Febiger; 1981

PMid: 7031601

6. World Health Organization (WHO), World Food Program (WFP), United Nations Standing Committee on Nutrition (UNSCN), United Nations Children's Fund (UNICEF). Community-based management of severe acute malnutrition; A Joint Statement by the WHO, WFP, UNSCN and UNICEF, 2007; Geneva, Switzerland
7. Ministry of Health and Family Welfare, Government of India. Operational guidelines on facility-based management of children with severe acute malnutrition. National Rural Health Mission, Ministry of Health and Family Welfare, 2011; New Delhi, India.

8. Humanitarian Charter and Minimum Standards in Disaster Response Geneva: The Sphere Project 2011, 3rd edition.

9. Briend A, Collins S. Therapeutic nutrition for children with severe acute malnutrition: summary of African experience. Indian Pediatrics 2010; 47:655-9.

https://doi.org/10.1007/s13312-010-0094-2

PMid: 20972282 